\title{
Effectiveness of Reflective Practice in a TA PeER- MENTORSHIP PROGRAM
}

\author{
Morgan O'Dea and Jeffrey Harris \\ Lassonde School of Engineering, York University \\ mo11iu@my.yorku.ca,jpharris@yorku.ca
}

\begin{abstract}
This paper reviews current teacher training practices and importance for post-secondary students. Specifically, the role of teaching assistants in tutorial settings are examined and how they impact student learning in an engineering program. Using Bandura's theory of self-efficacy and the reflective practitioner model, a TA mentorship pilot was developed and run during the 2018-2019 school year at York University. Results showed that participants were more confident managing their classrooms, guiding students through more difficult tasks, as well as felt more confident that their students would be successful in their tutorial setting.
\end{abstract}

Keywords: teaching assistants, training, professional development, self-efficacy, reflective practice

\section{INTRODUCTION}

Post-secondary education is often a multidimensional learning experience made up of both in-class teaching and hands on applications of concepts. For engineering students, challenging concepts being taught in upper year courses are often being learned for the first time and therefore it is important for students to have the most efficient learning environments both in class and during tutorials. Depending on the class, tutorials often are offered as an opportunity for students to ask questions and apply their classroom learning while under the supervision of a teaching assistant (TA). Because tutorials can play a crucial role to student learning and understanding of difficult concepts, it is important that the TA has the skills needed to engage with students, manage the classroom setting and provide instruction. Currently, there are no engineeringspecific teacher trainings available for TAs at the Lassonde School of Engineering, therefore research has begun to determine the relevance of such a program and how it should be offered for TAs to participate in. This paper will outline such research and the findings of the current pilot that ran during the 2018-2019 school year at York University.

Teacher development programs have been made more readily available for those taking up a teaching role across post-secondary institutions, especially with the recent integration of technologies in the classroom. As

summarised in [2], key factors of such teacher trainings can include: improvement of teaching and assessment practices, supporting and improving student learning, goals of higher education and understanding the learning development of students. Such teacher trainings are therefore crucial at the post-secondary level as it plays a large role in enhancing student learning and student educational experience.

In order to find a suitable impact evaluation on pilot participants, a literature review was conducted on previous teacher training programs to determine which factors were considered when determining the success of such programs. The theory of change was a prominent approach which deals with the long-term effects of the program but does not include how to measure such effects among participants [2]. In order for evaluation to be legitimate, the program must include meaningful criteria and indicators which describe what success means in terms of the program [2]. As laid out in [2], a theory of change should be developed for the program to detail what specific indicators the researchers are looking for, such as drivers for change, enabling factors, desirable outcomes and anticipated impact on the participants.

To enhance the understandings of how participants engage with and change in such programs, Bandura's Theory of Self-Efficacy is a prominent model used especially in educational settings [1]. As defined in [1], this theory measures and assess a person's beliefs about their own capabilities and successes when engaging in a certain activity, which in this context is teaching. Specifically, this theory models these perceptions based on personal factors and environmental influences, as well as how these perceptions can be altered depending on the context [1]. As participants become more confident in their teaching abilities, the more successful their actions play out in the classroom

To foster this increase in confidence, a reflective aspect was considered based on the model of reflective 
practitioner. According to [2], the reflective practitioner model is a common approach to understanding educational development and is founded on experimental learning, meaning action is informed by previous learning. As the participant engages in the reflection aspect of the program, they begin critically thinking about their actions in the classroom and how these actions have certain effects on students and their learning. This practice builds a relationship between action and reaction and will initiate the participant to begin brainstorming of ways to alter their actions in the classroom setting to produce a outcome that's leads to a more efficient tutorial [2].

Lastly, peer and self-evaluation was a common approach to teacher-training as it engages participants in collaborative learning [3]. As TAs engage in this peerevaluation, they can gain new information and perspectives outside their own, which allows them to engage in the remodelling of their teaching pedagogy as well as acquisition of new skills [4]. It also provides opportunity for collaboration with those who they previously may not have interacted with and therefore acts a net-working type of interaction which may benefit them in their future careers.

As many TAs who are facilitating tutorials at the Lassonde School of Engineering do not have previous experience in teaching roles, it is crucial that training becomes available for those who lack confidence in this role. As previously mentioned, it has been seen that teaching training in the post-secondary context is crucial for the further development and enhancement of the student learning experience, especially in the Engineering field as the concepts can become challenging for students to grasp and apply in upper years.

The initial thoughts for the program were that it was to include peer-collaboration between participants, as well as reflective components for TAs to engage in continuous learning outside of their tutorials. Reflecting on the literature review conducted, the pilot was developed to include peer-assessment, self-reflection and a pre/postprogram survey which aided in understanding participant's perception of tutorials, their roles, and their capabilities in the classroom.

At the end of the program, the most significant result showed that participants were more confident in their abilities in a teaching role. More specifically, TAs felt they had better classroom management skills, were able to facilitate more difficult tasks to their students and felt less anxious about being in a teaching position. Results also showed that peer-collaboration fostered their learning outside of their classroom as they were able to see firsthand how other participants ran their classroom and were able to incorporate new techniques into their own teaching practice.

\section{DEVELOPMENT OF THE MENTORSHIP PILOT}

When first brainstorming what components to include in the training pilot, the theory of change was used to break down both TA roles in tutorials as well as what we were looking for during the program.

\subsection{Teaching Assistant Role Breakdown}

Understanding what the roles of the TA in tutorials are is important when brainstorming how the program will be received by the TA, as well as how the program itself will be integrated into tutorials. TA roles can be broken down into: educator, facilitator, classroom management and building relationships.

TAs act as a secondary educator for their students as, depending on the course and tutorial, many students may look to their TA for extra clarification of topics and build on previous lessons provided during lectures. Along with this responsibility may come delivering additional lessons in a hands on way through question probing, providing inclass problems to solve, activities for students to work through in groups, and so on. TAs also act as an educator in that they are normally responsible for grading work handed in by the students, therefore are required to have a certain level of knowledge in order to accurately grade work.

TAs also act as a facilitator during tutorials as majority of the time it is the TA's responsibility to engage students in discussion as a class as well as in groups. Being able to do this requires the TA to know how to interact with students, which includes building positive rapport as well as engage in meaningful conversation. Being a successful facilitator also requires TAs to know how to manage a classroom, as many tutorials have more than 25 students attending. If the TA does not know how to keep students on task and undisruptive, the tutorial environment can quickly turn from productive to distracting, especially to those who are there to learn and require extra clarification.

Lastly, TAs must be able to build positive relationships with their students as majority of student inquiries are directed to the TA. Building these relationships can also lead to students becoming more empathetic during class and are more likely to listen and engage in a positive way to foster learning for themselves and their peers. Building relationships can include being available both during and outside classroom hours for feedback and questions. This can also include making accommodations for students who 
may require additional help or extra time for assignments due to extenuating circumstances.

\subsection{Theory of Change Framework Breakdown}

Table 1 outlines what outcomes we would hope to achieve at the end of the pilot and how this is going to aid in determining the success of the program. The headings include awareness of the current situation at the Lassonde School of Engineering, Enabling Factors in the Program, Process Activities, Desired Outcomes and Long Term Impact of the Program.

Table 1: Theory of Change Pilot Breakdown

\begin{tabular}{|c|c|c|c|c|}
\hline $\begin{array}{l}\text { Awareness: } \\
\text { What is the } \\
\text { current } \\
\text { situation? } \\
\text { What needs } \\
\text { to change? }\end{array}$ & $\begin{array}{l}\text { Enabling } \\
\text { Factors: } \\
\text { What are the } \\
\text { drivers that will } \\
\text { support change? }\end{array}$ & $\begin{array}{l}\text { Process } \\
\text { Activities }\end{array}$ & $\begin{array}{l}\text { Desired } \\
\text { Outcomes }\end{array}$ & $\begin{array}{l}\text { Long-Term } \\
\text { Impact }\end{array}$ \\
\hline $\begin{array}{l}\begin{array}{l}\text { Lack of } \\
\text { baseline } \\
\text { knowledge } \\
\text { requirement }\end{array} \\
\text { Differing } \\
\text { prior } \\
\text { teaching } \\
\text { experience } \\
\text { Disconnect } \\
\text { between } \\
\text { peer-practice } \\
\text { awareness } \\
\text { Lack of } \\
\text { classroom } \\
\text { management } \\
\text { techniques }\end{array}$ & $\begin{array}{l}\begin{array}{l}\text { Links to scientific } \\
\text { evidence }\end{array} \\
\text { Willingness to } \\
\text { improve } \\
\text { professional } \\
\text { skills/program } \\
\text { Faculty } \\
\text { support/resources } \\
\text { TA input and } \\
\text { suggestions for } \\
\text { improvement }\end{array}$ & $\begin{array}{l}\frac{1-2 \text { hour }}{\text { training }} \\
\text { day } \\
\text { Completing } \\
\text { entry } \\
\text { survey } \\
\text { - what is } \\
\text { your } \\
\text { perception } \\
\text { of peer- } \\
\text { evaluation } \\
\text { - what is an } \\
\text { effective } \\
\text { teacher } \\
\text { - } \\
\text { importance } \\
\text { of tutorials } \\
\text { Undergo } \\
\text { two peer- } \\
\text { evaluation } \\
\text { and } \\
\text { reflection } \\
\text { periods }\end{array}$ & $\begin{array}{l}\text { Understanding } \\
\text { of TA } \\
\text { perception of } \\
\text { teaching } \\
\text { abilities } \\
\text { Change in } \\
\text { teaching } \\
\text { assistant } \\
\text { perception of } \\
\text { their abilities } \\
\text { in tutorials } \\
\text { Positive } \\
\text { impacts of } \\
\text { peer- } \\
\text { evaluations on } \\
\text { teaching } \\
\text { abilities within } \\
\text { classrooms } \\
\text { Increased } \\
\text { participation } \\
\text { in teacher- } \\
\text { development } \\
\text { and training }\end{array}$ & $\begin{array}{l}\begin{array}{l}\text { Integration } \\
\text { of peer- } \\
\text { mentorship } \\
\text { program into } \\
\text { TA hiring } \\
\text { and training } \\
\text { Improvement } \\
\text { of TA and } \\
\text { student } \\
\text { relationships } \\
\text { Improved } \\
\text { student } \\
\text { experience } \\
\text { within } \\
\text { tutorials } \\
\text { Increased } \\
\text { enrollment } \\
\text { into program } \\
\text { Increase } \\
\text { productivity } \\
\text { within } \\
\text { tutorials }\end{array}\end{array}$ \\
\hline
\end{tabular}

When creating this breakdown, we focused on where there is current need for the program and why, how the program will be picked up by TAs as well as what factors will facilitate its integration, a rough summary of what may be included in the pilot and how the integration of the program will produced the desired outcomes.

\subsection{TA Mentorship Outline}

Using the previous information, it was decided that the program should be a mentorship-type program, where participants work together to provide feedback and discuss strategies that could be incorporated into their tutorials. Outside of these meetings, participants will also engage in self-assessment through completing reflections and creating goals for their own development in the program.

Table 2: Mentorship Program Stage Breakdown

\begin{tabular}{|l|l|l|l|}
\hline Stage 1: & Stage 2: & Stage 3: & Stage 4: \\
\hline Recruitment & Attend Tutorial 1 & Attend Tutorial 2 & $\begin{array}{l}\text { Complete Final } \\
\text { Reflection/Survey 2 }\end{array}$ \\
\hline $\begin{array}{l}\text { Completion Survey } \\
1\end{array}$ & $\begin{array}{l}\text { Provide Feedback } \\
\text { Tutorial Sign up }\end{array}$ & $\begin{array}{l}\text { Provide Feedback } \\
\text { Reflection (within 48 } \\
\text { hours ideally) }\end{array}$ & \\
\hline
\end{tabular}

Referencing Table 2, during the initial phase of the program, participants were given a baseline survey which was used to gain an initial understanding of their perceptions of tutorials, what their roles are as a TA, their confidence and abilities at performing specific teaching tasks and their impact on the students in their tutorial. Participants were also asked to reflect and brainstorm what they were hoping to get out of the program and what specific goals they were hoping to work towards. This program was participant-run; therefore, it was important early on for participants to understand that it was their responsibility to form these goals and think about what skills they were hoping to develop during the pilot.

Participants were then able to sign up to attend their peers' tutorials based on their availability and bring along a feedback form which included open ended questions regarding the preparedness of the TA, student engagement, and classroom management techniques that were used to ensure that the tutorial was running efficiently. At the end of the tutorial, the participants were then to engage in a small conversation about the tutorial and discuss what they believed worked well, what didn't and discuss ways to work toward reaching their desired goal in the program.

Within 24-48 hours after that tutorial, the participant was then to go home and engage in reflective practice using a provided guideline with open ended questions that would foster critical thinking about their performance in the tutorial and next steps for future tutorials.

At the end of the pilot, participants were then to fill out a post-program survey which included the same questions from the baseline, as well as more open-ended questions about the program. Both the baseline and post-program survey were to be filled in as honestly as possible and handed back to the research assistant. All other surveys were for the participant's learning throughout the program and were not collected.

Two pilots were run during the 2018-2019 year with a total of 6 participants being involved. The main purpose of these pilots was to collect data and feedback from participants on the relevance of the program for further 
development, hopefully becoming a teacher training program in the future that TAs will be able to participate in.

This research was approved by the Research Ethics Board (REB) at York University and has been assigned certificate e2018-255.

\section{RESULTS AND DISCUSSION}

Comparing feedback at the beginning and end of the program, surveys initial showed that participants scored between a 3-6 out of 10 on confidence levels in guiding students through difficult tasks, confidence in using classroom management skills and confidence in ensuring their students would be successful in their tutorial. On the final post-program survey, results from both pilots showed an increase in participant confidence in their teaching role, classroom management and ability to guide students through challenging tasks, whether that was in a lab setting or a tutorial setting, scoring between 8-10/10. Some participants also noticed a decrease in anxiety with regards to being in a teacher-role. This decrease in anxiety was attributed to TAs being able to go into their peer's tutorials and seeing first hand how other tutorials were being delivered and managed by participants other than themselves.

Besides an increase in confidence, the participants responded most positively to the peer collaboration and peer-assessment component of the program, as it provided a secondary opinion of what they as a facilitator may need to work on to be more successful. This collaboration also gave opportunity for peers to pick up new techniques used in other tutorials that they began adopting into their own teaching methods.

Lastly, some participants found the reflection component helpful as the feedback form engaged them in critical thinking and continuous learning with regards to how their tutorials went and what things they may change in their next tutorial.

With regards to their perception as a TA and their role in the classroom, examining their responses before and after the program there was very little change, in that participants felt tutorials should be student driven and that communication is a key aspect and therefore they must have good communication skills to be successful.

Due to the limited schedules of the participants and the limited number of participants, some did not receive as much feedback as others and therefore did not get the full experience of the program. For future programs, a schedule discussion between all participants will be included so that strategies and progress can be discussed in a more structured form. Also, seminars and in class trainings may become available for participants to engage in throughout the program as to ensure all participants are keeping up on their goals and they are able to learn new skills they may not be able to learn on their own time.

\section{CONCLUSIONS}

The importance of the availability of teacher training in post-secondary programs is crucial for ensuring that tutorials efficiently foster student learning. As tutorial's are often where Engineering students ask for clarification on difficult topics and begin applying their learnings, disruptive and ill-run tutorials can be detrimental to their learning progression. Currently, there are no permanent teacher training courses available for Engineering TAs, who often do not have prior teaching experience. After engaging in a training pilot which included reflection and peer assessment, TA participants were more confident in their ability to foster student learning and were less anxious engaging in a teaching role. In the future, more structure assessment and discussion will be incorporated to ensure equal learning and growth throughout the program.

\section{Acknowledgements}

We gratefully acknowledge the York University Academic Innovation Fund for supporting this research.

\section{References}

[1] Amy Dellinger, Jacquline Bobbett, Olivier Dianne and Chad Ellett, "Measuring teachers' self-efficacy beliefs: Development and use of the TEBS-Self', Teaching and Teacher Education, 2008.

[2] Diane Hart, Gabi Diercks-O'Brian and Adrian Powell, "Exploring stakeholder engagement in impact evaluation planning in educational development work", Evaluation, vol. 15, no. 3, pp. 285-306, 2009.

[3] Ineke Van den Berg, Wilfried Admiraal and Albert Pilot, "Peer assessment in university teaching: evaluating seven course designs", Assessment \& Evaluation in Higher Education, vol. 31, no. 1, pp. 19-36, 2006.

[4] Robert Machera, "Teaching intervention strategies that enhance learning in higher education," Universal Journal of Educational Research, vol. 5, no. 5, pp. 733-743, 2017. 


\section{APPENDIX A: PROGRAM SURVEYS}

\section{A.1 Pre-Program Survey}

\section{Part 1:}

This survey was designed to gain a better understanding of the perception of peerevaluation and teacher roles in tutorials. Please fill out the form below to the best of your ability, rating scenarios from: completely disagree (1) to completely agree (5)

\begin{tabular}{|l|l|l|l|l|l|}
\hline $\begin{array}{l}\text { Peer assessment is an effective way for me to receive formative } \\
\text { feedback }\end{array}$ & 1 & 2 & 3 & 4 & 5 \\
\hline Receiving peer assessment fosters my performance in the classroom & 1 & 2 & 3 & 4 & 5 \\
\hline $\begin{array}{l}\text { When I use self-assessment techniques, my performance in the } \\
\text { classroom is improved }\end{array}$ & 1 & 2 & 3 & 4 & 5 \\
\hline $\begin{array}{l}\text { When I use self-assessment techniques I am able to enhance my } \\
\text { teaching abilities }\end{array}$ & 1 & 2 & 3 & 4 & 5 \\
\hline $\begin{array}{l}\text { Using peer assessment prepares me to be more reflective and } \\
\text { productive }\end{array}$ & 1 & 2 & 3 & 4 & 5 \\
\hline $\begin{array}{l}\text { When I am productive in class my students are more likely to } \\
\text { participate and express their opinions }\end{array}$ & 1 & 2 & 3 & 4 & 5 \\
\hline $\begin{array}{l}\text { When I am prepared for class I am better able to manage my classroom } \\
\text { environment }\end{array}$ & 1 & 2 & 3 & 4 & 5 \\
\hline $\begin{array}{l}\text { When I am prepared for class I am more confident in leading my } \\
\text { classroom activities }\end{array}$ & 1 & 2 & 3 & 4 & 5 \\
\hline $\begin{array}{l}\text { Being an effective teacher to me means collaborating with my } \\
\text { colleagues }\end{array}$ & 1 & 2 & 3 & 4 & 5 \\
\hline I think the purpose of tutorials is to engage with students & 1 & 2 & 3 & 4 & 5 \\
\hline I believe tutorials are important for enhancing student learning & 1 & 2 & 3 & 4 & 5 \\
\hline Tutorials should be driven by the TA, not the students & 1 & 2 & 3 & 4 & 5 \\
\hline $\begin{array}{l}\text { Tutorials help both the student and the TA in their learning and } \\
\text { development of professional skills }\end{array}$ & 1 & 2 & 3 & 4 & 5 \\
\hline $\begin{array}{l}\text { It is important to me to facilitate meaningful conversation with my } \\
\text { students in tutorial }\end{array}$ & 1 & 2 & 3 & 4 & 5 \\
\hline Being an effective communicator is an important trait for a TA to have & 1 & 2 & 3 & 4 & 5 \\
\hline $\begin{array}{l}\text { My performance as a TA has a large impact on how my students learn } \\
\text { during tutorial }\end{array}$ & 1 & 2 & 3 & 4 & 5 \\
\hline $\begin{array}{l}\text { I am confident in my ability to guide students through difficult tasks } \\
\text { and/or assignments }\end{array}$ & 1 & 2 & 3 & 4 & 5 \\
\hline
\end{tabular}

Part 2:

This section of the questionnaire is designed to help gain a better understanding of the factors that create challenges for teachers and their ability to run activities/lessons during tutorials. Please indicate your opinion of each factor by circling the most accurate response.

I am able to shape tutorial content and classroom deliverables in my tutorials.
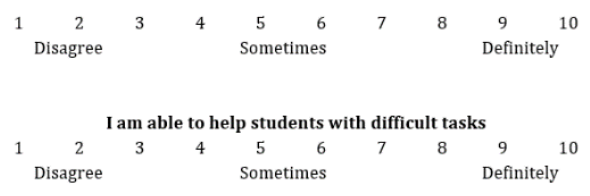

I am able to increase student memory about previous learning/tutorials

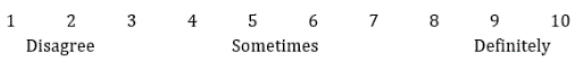

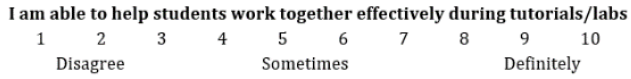

I am able to enforce classroom management strategies to control disruptive behavior

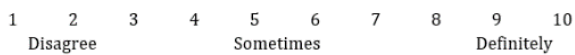

I am able to strategize with my co-TAs to improve teaching strategies

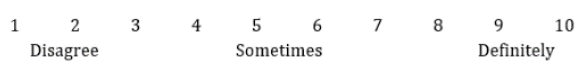

I am able to instill confidence in my students to succeed in my class/tutorial

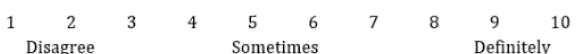




\section{A.2 Post- Program Survey}

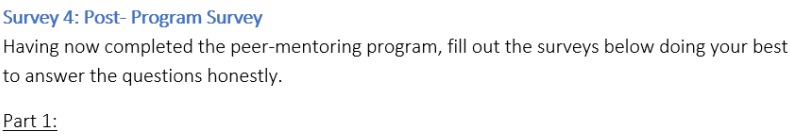

12) Tutorials help both the student and the TA in their learning and development of professional skills:

$$
\begin{array}{lllll}
1 & 2 & 3 & 4 & 5
\end{array}
$$

13) It is important to me to facilitate meaningful conversation with my students in tutorial:

$$
\begin{array}{lllll}
1 & 2 & 3 & 4 & 5
\end{array}
$$

14) Being an effective communicator is an important trait for a TA to have:

$$
\begin{array}{lllll}
1 & 2 & 3 & 4 & 5
\end{array}
$$

What other traits do you believe are important for TAs to have?

15) My performance as a TA has a large impact on how my students learn during tutorial:

$$
\begin{array}{lllll}
1 & 2 & 3 & 4 & 5
\end{array}
$$

16) I am confident in my ability to guide students through difficult tasks and/or assignments:

$$
\begin{array}{lllll}
1 & 2 & 3 & 4 & 5
\end{array}
$$

Part 2

This section of the questionnaire is designed to help gain a better understanding of the factor that create challenges for teachers and their ability to run activities/lessons during tutorials. Please indicate your opinion of each factor by circling the most accurate response.

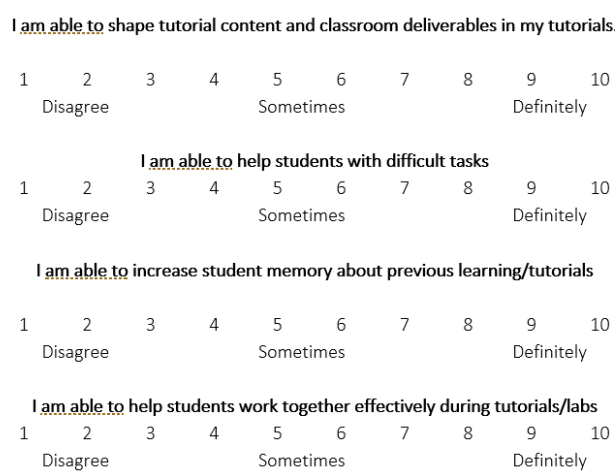

I am able to enforce classroom management strategies to control disruptive behavior

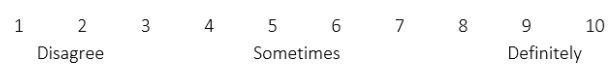

I am able to engage positively with students during tutorials and provide a positive classroom environment

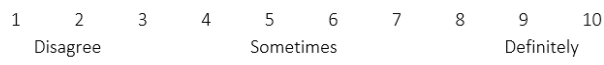

I am able to strategize with my co-TAs to improve teaching strategies

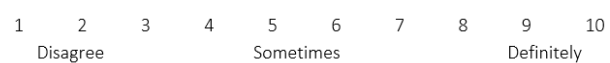

I am able to instill confidence in my students to succeed in my class/tutorial

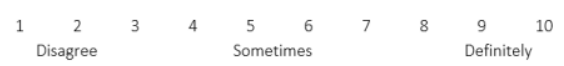

Part 3:

This last section is designed to gather feedback on your opinion of the program and its relevance to teaching assistants at York. Please answer each question honestly and with as much detail as possible.

Which parts of the program did you find to be most useful/relevant to your role as a teaching assistant, if any?

If given the chance, would you participate in this program again? Why? What would you change about the program? Explain.

How accurate do you believe your peer-evaluator's feedback was in regards to the success in your tutorials?

Did your understanding of teaching effectiveness change as a result of this program? Which parts instilled this?

Do you believe your classroom management techniques have improved?

Are you more comfortable receiving feedback from peers? 